\title{
İntraoperatif Malign Hipertansiyon ile Ortaya Çıkan Feokromasitoma Olgusunda Anestezi Yönetimi
}

\section{Intraoperative Malignant Hypertension and Postoperative Pheochromacytoma:} Anesthetic Management

\author{
Mehmet Şirin Gökhaner ${ }^{1}$, Esra Ozayar ${ }^{1}$, Aysun Kurtay', Handan Güleç ${ }^{2}$, Eyüp Horasanlı ${ }^{2}$ \\ 1 Keçiören Eğitim Araştırma Hastanesi, Keçiören/ANKARA \\ 2 Yıldırım Beyazit Üniversitesi, Ulus/ANKARA
}

ÖZET

Feokromositoma nadir görülen katekolamin üreten hipertansiyon, taşikardi, terleme, çarpıntı, baş ağrısı ve anksiyete ataklarına neden olan nöroendokrin bir tümördür. Genellikle anestezi indüksiyonu ve cerrahi manuplasyonlar sırasında katekolaminlerin kontrolsüz yüksek miktarda salınımı olmakta ve kardiyovasküler instabilite görülmektedir. Özellikle bu durum tümör rezeksiyonu sırasında artmaktadır (1). Bu hastalarda yoğun bir preoperatif hazırlık ve yakın takip gerektiren intraoperatif ve postoperatif bakım hayati önem taşımaktadır (2)

Önceden tanısı olmayan bu tür hastalarla sürrenal cerrahi dışındaki cerrahilerde de karşılaşmak mümkündür. Intraoperatif malign hipertansiyon feokromasitomayı akıllara getirmeli ve postoperatif gerekli tetkikler yapılmalıdır. Biz de bu olgumuzda ortopedik cerrahi sırasında intra- operatif malign hipertansiyon atakları olan ve postoperatif dönemde feokromasitoma tanısı alan bir olgumuzu paylaşmayı amaçladık

Anahtar Kelimeler: Feokromasitoma,Anestezi Yönetimi,Hipertansiyon
SUMMARY

Pheochromocytoma is a rarely seen neuroendocrine tumor that causes hypertension, tachycardia, sweating, palpitations, headache and anxiety. Excessive cathecolamin release can occur during surgical manipulation and induction of general anesthesia. Particularly this release can increase during resection of tumor (1). In these clients, a meticulous preoperative preperation and perioperative close monitorisation is important (2). It is possible to come up with these patients which are not diagnosed before, during surgeries other than surrenal surgery. Intraoperative malignant hypertension should bring pheochromacytoma in minds and postoperative tests should be done for diagnosis. In this report we aimed to share a case which had malignant hypertansive crisis during ortophedic surgery and diagnosed as a pheochromocytoma postoperatively.

Key Words: Pheochromocytoma,Anesthetic Management,Hypertension 


\section{OLGU}

Yetmiş beş yaşındaki erkek hastaya ,femur kırığı nedeni ile proksimal femoral çivi operasyonu planlandı. Hastanın preoperatif değerlendirmesinde, koroner arter hastalığı, hipertansiyon, kronik obstrüktif akciğer hastalığı, tip II diabetes mellitus ve kronik böbrek yetmezliği olduğu tespit edildi.Hastanın anamnezinde ara ara baş ağrıların olduğu öğrenildi. Hastanın kullandığı ilaçlar kalsiyum kanal blokeri (amlodipin), inhaler ajanlar (salbutamol), ACE inhibitörleri (ramipril), antitrombotik ajan (asetilsalisilik) olarak kaydedildi. Preoperatif kan tetkikleri: Hgb:9.7gr/ dL, Plt:222000/uL, Htc:30.2 \% , INR:1.12, Kre- atin:2.14 $\mathrm{mg} / \mathrm{dL}$, Üre:64 $\mathrm{mg} / \mathrm{dL}$ Sodyum:140 $\mathrm{mmol} / \mathrm{L}$, Potasyum:4.0 mmol/L, sT3:1.78 pg / mL, sT4:1.28 $\mathrm{ng} / \mathrm{dL}, \mathrm{TSH}: 1.09 \mathrm{ulU} / \mathrm{mL}$ ALT: $20 \mathrm{U} / \mathrm{L}$, AST:16 U/L. Hastanın preoperatif ilgili konsültasyonları (kardiyoloji, göğüs hastalıkları, nefroloji birimi ) tamamlandı. Gerekli öneriler yapıldıktan sonra hasta, elektif olarak operasyona alındı. Hasta için spinal anestezi planlandı. Hastaya intravenöz $0.5 \mathrm{mg}$ midazolam sedas- yon amaçlı yapıldıktan sonra hasta monitorize edildi. Hastanın preoperatif kan basıncı $130 / 70 \mathrm{mmHg}$, nabız:90atım/dk, periferik oksijen sa- turasyonu \%95 idi. Hasta ortopedi doktoru eşliğinde yavaşça ameliyat masası üzerinde oturtuldu. Lomber bölge sterilite şartlarına uygun bir şekilde baticonile silindi. L3-L4 aralığından 25 G spinal iğne ile subaraknoid aralığa girildi. Serbest BOS gelişi görüldükten sonra subaraknoid aralığa 15 mg bupivakain (3 cc \%0.5 bu- pivakain spinal heavy) enjekte edildi. Sonrasında hasta supin pozisyona alındı. Spinal blok sonrası 4. dakikada hastada kan basıncı:95/60 mmHg,nabız:100 atım / dk olarak gözlendi.Has- taya hemen iv $5 \mathrm{mg}$ efedrin yapıldı ve hızlıca 500 cc serum fizyolojik verildi.Sonrasında hastanın kan basıncının 125/75mmHg olduğu görüldü. Pinprick testi ile hastanın duyusal blokajının T10 seviyesine kadar yükseldiği tespit edildikten sonra,operasyonun başlanmasına izin verildi. Hastanın steril bir şekilde boyanması ve cerrahi örtüler ile örtülmesi esnasında hastanın kan basıncı ve nabızı normal seyretti. Cerrahinin cilt insizyonu ile birlikte (spinal bloktan $20 \mathrm{dk}$ sonra) hipertansif ataklar görülmeye başlandı. Hastaya radial arterden invaziv arter monitorizasyonu yapıldı. Ani yükselen kan basıncının $340 / 120$ mmHg ye kadar (Şekil 1) yükseldiği görüldü. Tansiyon atakları esnasında hastada KiBAS bulguları (baş ağrısı, bulantı -kusma, bilinç değişiklikleri) gözlenmekteydi. Kan basıncı değişikliklerine bağı baş ağrısı olan, anksiyetsi yükselen hastaya ara ara $0.5 \mathrm{mg}$ midazolam (toplam $2 \mathrm{mg}$ ) yapıldı Hastaya esmelol infüzyonu; 30 saniyede $1 \mathrm{mg} / \mathrm{kg}$ bolus doz ve sonrasında $300 \mathrm{mcg} / \mathrm{kg} / \mathrm{dk}$ ya kadar varan dozlarda idame olarak uygulandı. Kan basıncının kontrol altına alınamaması nedeniyle $10 \mathrm{mcg} / \mathrm{kg} / \mathrm{dk}$ dozundan nitrogliserin infüzyonu başlatılarak tedrici olarak artıııldı. Hastanın kan basıncında ani düşmeler yaşanıldığı durumda antihipertansiflerin dozu hızla azaltılarak gereğinde infüzyona son verildi. Hastaya yakın takip yapılarak kan basıncındaki ani değişiklikler, antihipertansiflerin dozu hızla değiştirilip kontrol altına alındı. Intraoperatif kardiyoloji konsültasyonu istenen hastada iskemik değişikliklere rastlanmadı. intraoperatif 500 cc'ye yakın kanama oldu. Hastaya 2 ünite eritrosit süspansiyonu replase edildi. Hastanın operasyonu sonlanıncaya kadar hipertansif-hipotansif ataklar gözlendi. Operasyon bitiminde, hasta nitrogliserin infüzyonu eşliğinde postoperatif yoğun bakım ünitesinde takibe alındı. Postoperatif kan tetkikleri; $\mathrm{Hgb}: 10.27 \mathrm{gr} / \mathrm{dL}$, PIt:322000/uL INR:1.39, Kre- atin:2.05 mg/dL, Üre:75, Sodyum:137mmol/L, Potasyum:4.72mmol/L, ALT: $30 \mathrm{U} / \mathrm{L}$,AST:20 U/L. Hastaya feokromasitoma ön tanısı nedeni ile üst abdomen BT planlandı. KBY nedeni ile Kreati- nin:2 $\mathrm{mg} / \mathrm{dL}$ olan hastaya kontrastsı BT tetkik çekildi. Çekilen üst abdomen tomografisi sonucunda sol adrenal bezde $28 \times 29 \mathrm{~mm}$ boyutunda $28 \mathrm{HU}$ dansitesinde noduler lezyon (Şekil 2) tes- bit edildi. Yoğun bakımda, hastanın 24 saatlik idrarı toplatılıp tetkik edildiğinde, katekolamin metabolitlerinden metanefrin ve normetanef- rinin (Şekil 3) arttığı görüldü. Hastaya alfa-bir bloker (doksazosin $8 \mathrm{mg}$ ) ve kalsiyum kanal blokeri (amlodipin $10 \mathrm{mg}$ ) başlanarak tedavi altına alındı. Tansiyon atakları düzelen hasta ileri tetkik ve tedavi için dahiliye servisine postoperatif 3 . günde devredildi. 


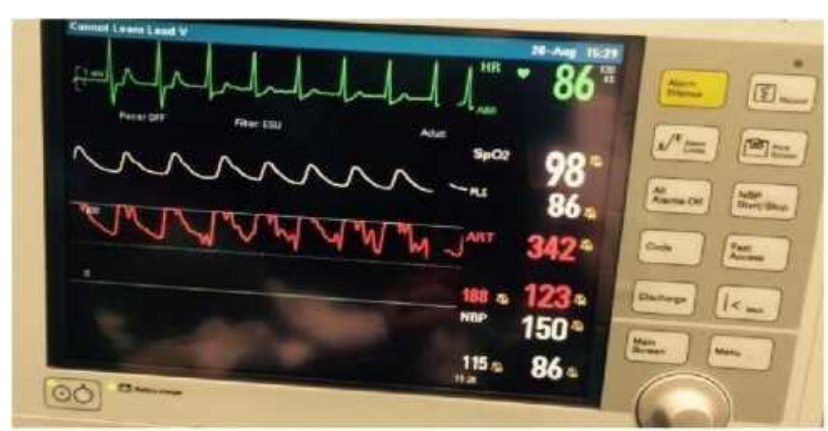

Şekil 1: Hipertansif atakların invaziv arter monitorizasyonunda gösterilmesi.
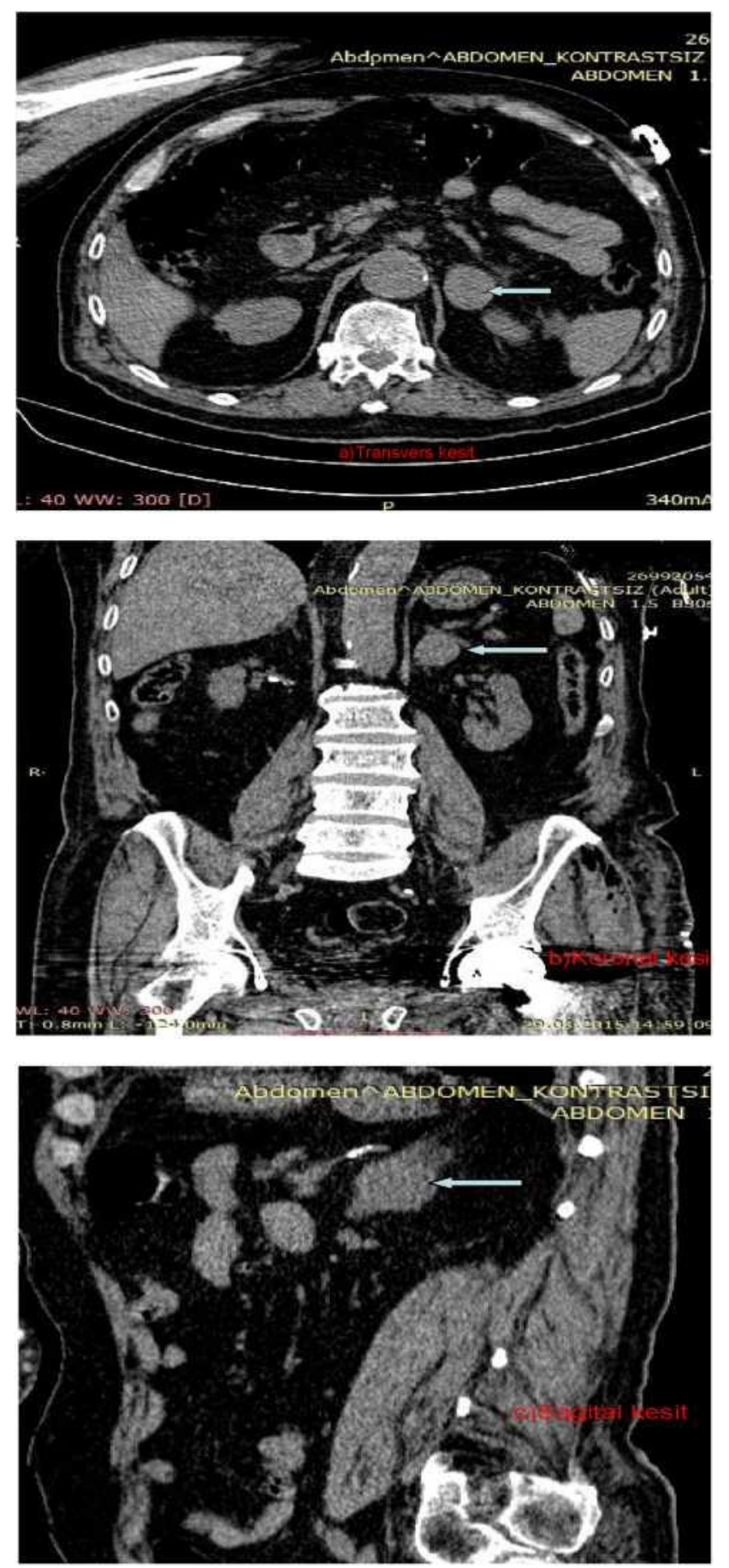

Şekil 2: sol adrenal bezde $28 \times 29 \mathrm{~mm}$ boyutunda $28 \mathrm{HU}$ dansite- sinde noduler lezyon(oklar) a) Postop 3.gün

\begin{tabular}{|c|c|c|}
\hline Test Adı & Sonuç & Bilim \\
\hline$M \ll \tan ^{*}$ frın & W9.0 & $\mathrm{p}^{*} \operatorname{tt} 4^{*} \mathrm{~W}^{*} \mathrm{M}(m-» 0)$ \\
\hline No<mttan ${ }^{*}$ frin & wo« & \\
\hline Adrtnabn & 330 & u»? $4 \mathrm{t}^{*}$ al HO-21) \\
\hline Noudrtnalm & 509 & $\mathrm{M}>04 ? \mathrm{ME} \mathrm{N}(15-80)$ \\
\hline Volüm & 2300 & 0 \\
\hline
\end{tabular}

b) Postop 14.gün

\begin{tabular}{|c|c|c|}
\hline Test Adı & Sonuç & Birim \\
\hline Melanefrin & 400,1 & $\mathrm{MO} / 24 \mathrm{sa}^{\wedge} \mathrm{H}(30-350)$ \\
\hline Normetanefrin & 592.7 & P0/24sa*^H(1i8-560) \\
\hline Adrenalin & 91 & $V \& 2 *$ saat $N(0 \bullet 21)$ \\
\hline Noradrenalin & 352 & $\mathrm{pg} / 24 \mathrm{saat}$ NC1S-80) \\
\hline Oopamın & 3078 & $\mathrm{pg} / 24$ saat $\mathrm{N}(65 \bullet 400)$ \\
\hline Volüm & 3100 & 0 \\
\hline
\end{tabular}

Şekil 3: Postoperatif 24 saatlik idrarda katekolamin metabolitleri.

\section{TARTIŞMA}

Feokromasitoma adrenal medulladaki kro- mafin hücrelerinden ya da sempatik sinir sisteminin diğer paraganglionlarından kaynaklanan bir tümördür $(3,4)$. Feokromasitoma yılda her bir milyonda 2-8 oranında görülür (5). Adrenal bezlerin dışında bulunan kromafin hücrelerin son ürünü norepinefrin olduğu halde adrenal bezdeki son ürün epinefrindir. Tümör $\% 80$ unilateral ve soliter, \%10 bilateral, \%10 ekstraadre- nal yerleşimlidir (3). Feokromasitomalı hastaların \%90'ında hipertansiyon olmasına karşın bu hastaların yarısında değişken kan basıncı profili varken \%40'ında sadece paroksismal hipertansiyon vardır. Tedaviye dirençli hipertansiyonu ve paroxismal semptomları olan hastalarda feokromasitoma öncelikli olarak düşünülmelidir $(5,6)$. Hastalarda dolaşımdaki epinefrin, norepinefrin ve dopamin salınımına bağlı olarak çeşitli semptomlar görülür.Norepinefrin salgılayan tümörü olan hastalar ciddi ve tedaviye dirençli hipertansiyon ile beraberken epinefrin ve dopamin salgılayan tümörlü hastalar taşikardi ile birlikte çarpıntı,terleme, baş ağrısı, flushing, solukluk, titreme, panik ve korku gibi değişik semptomlar gösterir (6). Bu tümörlerin maniplasyonu hipertansif krizi tetikleyebilir. Bundan dolayı cerrahi öncesi doğru tanı önemlidir (4).

Feokromasitoma tanısı için plazma ve idrar katekolamin ve katekolamin yıkım ürünlerinin tespiti ile görüntüleme yolları (BT, MRI) kullanılır 
(6). Olgumuzda postoperatif dönemde, 24 saatlik idrarda katekolamin yıkım ürünlerinin artığını ve tomografik görüntülemede sol sürrenal bölgede nodüler lezyonu gözlemledik.

Feokromasitomada preoperatif hazırlıkta altın standart; hastanın kan baıncı, kalp hızının kontrol altına alınması ve sıvı replasmanı sağlanmasıdır (7). Böylece anestezi indüksiyon, entü- basyon ve cerrahi tümör rezeksiyonu sırasında istenmeyen olaylara yol açabilecek adrenerjik kriz engellenebilecektir. Bizim olgumuzda, preoperatif feokromasitoma tanısı olmadığından, feokromasitomaya yönelik preoperatif hazırlık yapılmamıştı. İntraoperatif hipertansif atakları, beta bloker (esmolol ) ve nitrogliserin infüzyonu ile kontrol altına almaya çalıştık.

Sempatik sinir sistemini stimule eden, katekolaminlerin disritmi yapıcı etkilerini potansiya- lize eden veya histamin salınımına neden olan anestezik ilaçlar veya anestezi teknikleri hipertansiyon gelişimini indükleyebileceğinden kaçınılmalıdır (8). Femur protezi için spinal anestezi altında olgumuzun opere olması, sempatik blokaj sağlandığından hipertansiyonu kısmen engellemiş olabilir.

Sarıcaoğlu ve arkadaşları da yine intraoperatif hipertansiyonla belirlenen bir feokromasitoma olgusunu sunmuşlardır. Preoperatif hipertansiyon regülasyonu için nifedipine ve sodyum nit- roprussid kullanmışlardır (9).

Paix ve ark (10), anestezi süresince ani hipertansiyon krizlerinin kontrolünde hızlı ve dikkatli bir şekilde sebebin bulunarak volatil ajanlar, i.v opioidler ve hızı etkili antihipertansif ajanlarla kontrol altına alınmasının ciddi şekilde morta- liteyi önlediğini bildirmişlerdir. Bunun yanında tedaviye yanıt vermeyen inatçı hipertansiyon varlığında feokromasitoma, karsinoid sendrom ve tiroid krizi gibi daha nadir sebeplerin düşünülmesinin önemini belirtmişlerdir. Bizim olgumuzda, feokromasitoma ön tanısı düşünülüp postoperatif dönemde ona göre tetkik edilmiş ve kesin tanıya ulaşılmıştır.

Cerrahiye hazırlanan hastalar 2 haftalık bir tedavi ile tam a-blokaj ve kan volüm restorasyonuna tutulmalıdır. Feokromasitoma cerrahisinde anestezi uygulamaları potansiyel güçlükler taşımaktadır. Operasyon esnasında maniplasyonlara bağlı olarak katekolaminlerin aşırı salınması görülebilmektedir (11). Adrenerjik blokaj için fen- tolamin, prozasin, doksazosin kullanılır. Bunun yanında intraoperatif krizlerde a- blokerlerin yanında ß-blokerler, Ca kanal blokerleri, magnezyum gibi değişik medikal tedaviler başarı ile kullanılmıştır (6). Biz de olgumuzun postoperatif döneminde tansiyon regülasyonunu abloker (doksazosin) ve Ca kanal blokerleri (amlodipin) ile sağladık.

Intraoperatif ani gelişen malign hipertansiyon olgularında feokromasitomanın akılda tutularak postoperatif tetkiklerin yapılarak erken tanıya gidilmesi ve uygun medikal yaklaşımın, hastanın mortalite ve morbidite oranında önemli azalma sağlayacağı kanaatindeyiz.

\section{KAYNAKLAR}

1. YuanShaoa, M, RanChena, M, Zhou-junShena, et al. Preoperative alpha blockade for normotensive pheochromocytoma: is it necessary? J Hypertension 2011;29:2429 2432.

2. Kurt E, Ayaz Y. Adrenal Sistem ve Anestezi. Turkiye Klinikleri J AnestReanim-Special Topics 2008;1:53-67.

3. C. Prys-Roberts. Phaeochromocytoma-recent progress in its management. British Journal of Anaesthesia 2000;85(1): 44-57

4. Blake MA, Krishnamoorthy SK, Boland GW et al. Low- density pheochromaon CT: A mimicker of Adrenal adenoma. AJR Am J Roentgenol 2003;181(6):1663-8

5. Paul G. Barash, Buruce F. Cullen, Robert K. Stoelting. Clinical Anesthesia Fourth Edition Lippincott Williams\&Wilkins p:1130-3

6. Kudva YC, Sawka AM, YoungW. The laboratory diagnosis of adrenal pheochromocytoma: the mayo clinic experience. J Clin Endocrinol Metab 2003;88(10):4533-9
8. Michelle A.O. Kinney, Bradly J. Narr, and Mark A. Perioperative Management of Pheochromocytoma. J CardiothorandVascAnesth 2002;16:359-369.

9. Morgan GE, Mikhail MS,Murray MJ, Larson CP. Clinical Anesthesiology, (Anesthesia for Patients with Endocrine Disease), 3rd ed. United States of America: Lange Medical Books 2002;36:747-8

10. Sarıcaoğlu F, Öç B, Kanbak M, Aypar Ü. İntraoperatif hipertansiyon ile belirlenen feokromasitoma (Olgu Sunumu) Anestezi Dergisi,11:231-234, 2003

11. Paix $A D$, Runciman $W B$, Horan $B F$, Chapman MJ, Currie M. Crisis management during anaesthesia: hypertension. Qual Saf HealtCare 2005;14 (3): 12-3

12. P. Tauzin-Fin, M. Sesay, P. Gosse, P. Ballanger. Effects of periopertavi a1 block on haemodynamic control during laparoscopic surgery for phaeochromocytoma. British Juornal of Anaesthesia 2004:92(4):512-7. 